\title{
Stepwise Introduction of Regulatory Genes Stimulating Production of $\alpha$-Amylase into Bacillus subtilis: Construction of an $\alpha$-Amylase Extrahyper Producing Strain
}

\author{
Kazumasa Hitotsuyanagi, ${ }^{*}$ Kunio Yamane and Bunji Maruo \\ Institute of Applied Microbiology, The University of Tokyo, \\ Bunkyo-ku, Tokyo, Japan \\ * Shimonoseki Women's Junior College, Yamaguchi-ken
}

Received June 15, 1979

\begin{abstract}
The production of extracellular a-amylase in Bacillus subtilis is probably regulated by many genetic elements, such as $a m y R, \operatorname{tmr} A 7, p a p, a m y B$ and $\operatorname{sac} U$. Additional genetic elements, $C-108$ and A-2 for production of the $\alpha$-amylase were found in D-cycloserine and ampicillin resistant mutants (C108 and A2) of B. subtilis 6160, respectively. Strain C108 increased the production of $\alpha$-amylase about 5 times and protease about 80 times compared to parental 6160 strain. Strain A2 showed a nearly 6 -fold increased $\alpha$-amylase production.

These genetic elements displayed a synergistic effect with other genetic factors in production of extracellular $\alpha$-amylase when these elements were transferred by DNA mediated transformation. By stepwise introduction of these and other genetic elements into B. subtilis 6160 by transformation and mutation, strains with higher $\alpha$-amylase producing activity were obtained. The finally obtained strain, T2N26, produced about 1,500 2,000 times more $\alpha-$ amylase than parental 6160 strain.
\end{abstract}

$\alpha$-Amylase is one of several extracellular enzymes of Bacillus subtilis. Most of $\alpha-$ amylase produced is localized in culture medium, and a small amount is found in the cells. In production of this extracellular $\alpha$ amylase, at least two major regulation systems can be considered. One is a regulation system for transcription and translation of the structural gene of $\alpha$-amylase (amyE), and the other is for secretion of the synthesized or synthesizing $a$-amylase peptide through bacterial membrane and cell wall to the culture medium. Since $\alpha$-amylase of $B$. subtilis is composed of a single polypeptide chain, ${ }^{1 \sim 3)}$ the effect of other regulatory steps such as formation of subunit structure or binding of prosthetic groups to the synthesized protein may not be present.

Regulatory genes for production of extracellular $\alpha$-amylase in $B$. subtilis, $\left.\operatorname{am} y R,{ }^{4,5}\right)$ pap, ${ }^{\theta, 7)} \operatorname{tmr} A 7^{8,9\}} a m y B^{10)}$ and $\operatorname{sac} U^{111}$ have been reported. Among them, amyR is a specific regulatory gene for production of $\alpha$ amylase. " $t m r A 7$ shows tunicmycin resistant characteristic and hyperproduction of $\alpha$-amylase simultaneously but not hyperproduction of protease and ribonuclease. ${ }^{8)}$ Tunicamycin is an antiviral antibiotic in animal cells ${ }^{12}$ and it inhibits the biosynthesis of peptidoglycan ${ }^{13}$ and teichoic acid ${ }^{14}$ by preventing formation of lipid-intermediate(s). The loci of $a m y R$ and $t m r A 7$ are located very closely to $a m y E$ on the chromosome. ${ }^{93}$

On the other hand, pap showed a pleiotropic effect: strains carrying the mutation showed not only hyperproduction of extracellular $\alpha$ amylase, neutral protease and alkaline protease, but also loss of flagellation and motility. ${ }^{6,15)}$ Steinmetz et al. ${ }^{16)}$ reported that pap-9 $a m y B$ and $\operatorname{sac} U$ mutations were identical with respect to their pleiotropic phenotype and all three loci were located near his $A$ and gtaB loci on the chromosome.

In this paper we describe the isolation of two new $a$-amylase hyperproducing mutants, $\mathrm{C} 108$ and $\mathrm{A} 2$, and the construction of an $\alpha$-amylase extrahyper producing strains by stepwise introduction of these mutations and other 
beneficial genetic elements into $B$. subtilis 6160 using DNA mediated transformation and mutation.

\section{MATERIALS AND METHODS}

Strains and media. Strains used in this experiment are listed in Table I. B. subtilis 6160 is a derivative of the transformable strain of $B$. subtilis Marburg 168 . The composition of bouillon-yeast extract (BY) medium was described previously ${ }^{17)}$ and $A B Y$ medium is twice concentrated BY medium containing $10 \%$ soluble starch.

Isolation of mutants by $N$-methyl- $N^{\prime}$-nitro- $N$-nitrosoguanidine (NTG) treatment. Exponentially growing cells in BY medium were harvested and washed once with $50 \mathrm{~mm}$ Tris(hydroxymethyl)aminomethane-maleate buffer, $\mathrm{pH}$ 6.0. After they were suspended in the same buffer, cells were incubated with $150 \mu \mathrm{g}$ of NTG per ml at $37^{\circ} \mathrm{C}$ as described by Adelberg et al ${ }^{18}$ ) Treated cells were collected on a nitrocellulose membrane filter, washed and grown at $37^{\circ} \mathrm{C}$ for $6 \mathrm{hr}$ in $\mathrm{BY}$ medium. The culture was plated on BY medium agar plates containing various antibiotics.

Assay of amylase activity. Amylase activity was assayed by the modified method of Fuwa. ${ }^{1 \theta)}$ As substrate, $0.5 \%$ soluble starch in $0.04 \mathrm{M}$ phosphate buffer, pH 7.3, was used.

Assay of protease activity. Casein hydrolytic activity of protease was assayed by the modified method of Nakamura. ${ }^{20)}$ One milliliter of $0.6 \%$ casein in $50 \mathrm{~mm}$ phosphate buffer, $\mathrm{pH} 7.3$, was mixed with $0.2 \mathrm{ml}$ of enzyme solution. After the mixture was incubated at $40^{\circ} \mathrm{C}$ for an appropriate time (usually $10 \mathrm{~min}$ ), $4 \mathrm{ml}$ of $6 \% \mathrm{HClO}_{4}$ was added to terminate the reaction. The insoluble part of the mixture was filtered through Toyo-Roshi filter-paper, $\mathrm{No} .2 ; 4 \mathrm{ml}$ of $0.8 \mathrm{M} \mathrm{Na} \mathrm{Na}_{3}$ and $1 \mathrm{ml}$ of the Folin-Ciocalteau phenol reagent was added to $1 \mathrm{ml}$ of filtrate; and absorbance at $655 \mathrm{~nm}$ was measured by a spectrophotometer. One unit of enzyme activity was defined as that amount of enzyme which increased 0.001 in absorbance by enzyme reaction at $40^{\circ} \mathrm{C}$ per min.

Assay of amylase and protease productivity on agar plates. Amylase productivity on agar plates was determined by measuring the halos around colonies grown in BY medium agar plates containing $1 \%$ soluble starch after $0.01 \mathrm{M} \mathrm{I}_{2}$-KI solution was sprayed on plates. Protease productivity on agar plates was determined by measuring the halos around colonies grown in BY medium agar plates containing $1 \%$ casein.

Transformation procedures. Transforming DNAs were prepared from donor strains by the phenol-pH 9

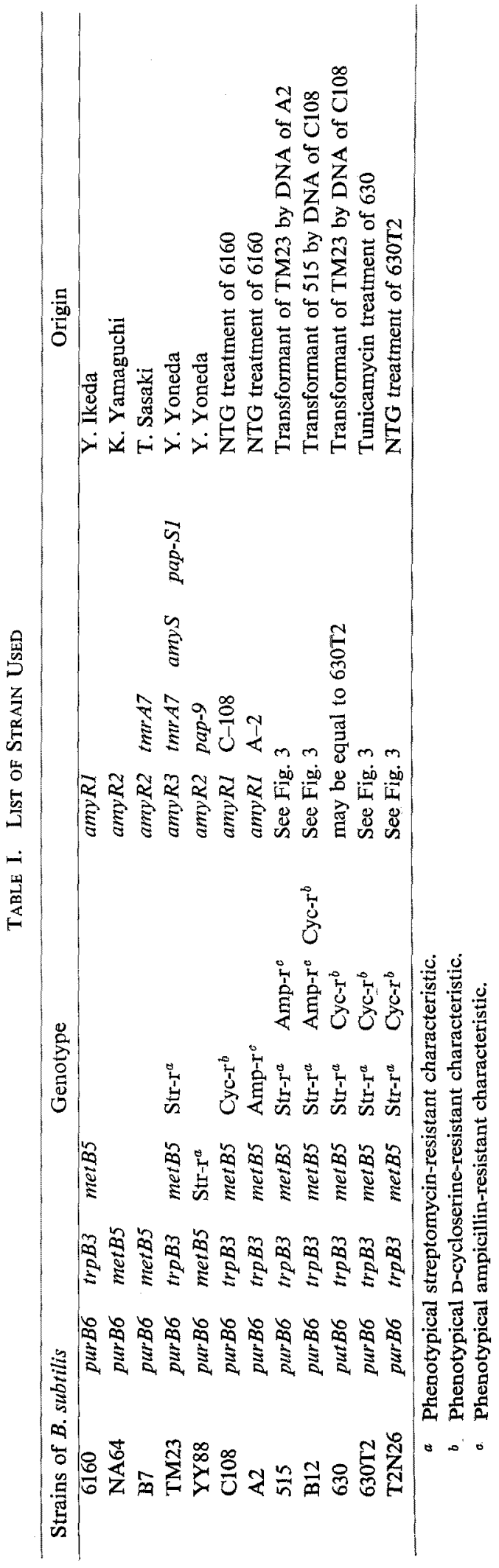


method of Saito and Miura. ${ }^{21)}$ Transformation experiments were carried out as described by Yoshikawa. ${ }^{22}$

Disc gel electrophoresis. Sodium dodecyl sulfate (SDS) disc gel electrophoresis was carried out by the method of Laemmli. ${ }^{23)}$ Samples were boiled for $5 \mathrm{~min}$ in a mixture of $1 \%$ SDS and 2-mercaptoethanol and applied to the gels.

\section{RESULTS}

Isolation of a-amylase hyperproducing strains (C108 and A2) among antibiotic resistant mutants

From mutagenized $B$. subtilis 6160 , mutants resistant to minimum inhibitory concentrations of penicillin, ampicillin and D-cycloserine were isolated. Minimum inhibitory concentrations of the three antibiotics for strain 6160 were $2 \mu \mathrm{g}$ for penicillin, $1 \mu \mathrm{g}$ for ampicillin and $200 \mu \mathrm{g}$ for $\mathrm{D}$-cycloserine per $\mathrm{ml}$ of BY medium.

From about 5,000 D-cycloserine resistant mutants, 200 colonies appeared to show hyperproductivity of $\alpha$-amylase and/or protease in the assays of BY medium agar plates containing $1 \%$ starch or $1 \%$ casein, and they were cultured in BY medium containing $4 \%$ soluble starch at $30^{\circ} \mathrm{C}$ for $48 \mathrm{hr}$. The highest $\alpha$-amylase producer (C108) among them was selected and used in further experiments. The strain produced about 5 times as much $\alpha$-amylase and about 80 times as much protease compared to the parental 6160 culture.

From about 3,000 ampicillin resistant mutants, 100 colonies of $\alpha$-amylase and/or protease hyperproducers as judged from plate screening were cultured in BY medium containing $4 \%$ starch at $30^{\circ} \mathrm{C}$ for $48 \mathrm{hr}$. The highest $\alpha$-amylase producer (A2) was selected and used in further experiments. The strain produced about 6 times as much $\alpha$-amylase as 6160 , but protease production in A2 was the same as in the original strain.

No hyperproducer of $\alpha$-amylase and/or protease was isolated from about 3,000 penicillin resistant colonies.

Kanamycin and refampicin resistant mutants were also isolated from the mutagenized 6160 culture, but no hyperproducer of $\alpha$-amylase was isolated.

\section{Genetic characteristics of $A 2$ and $\mathrm{Cl} 108$}

To determine whether the hyperproductivity of $\alpha$-amylase and ampicillin resistance (Amp-r) in A2 and whether that of $\alpha$-amylase in combination with protease and $\mathrm{D}$-cycloserine resistance (Cyc-r) in $\mathrm{C} 108$ were introduced by single or different mutations, DNAs from A2 and $\mathrm{C} 108$ were prepared and were transferred into 6160 by DNA mediated transformation (Table II). Four hundred and twenty each transformants acquired Amp-r or Cyc-r characteristic were tested for the $\alpha$-amylase productivity. But no transformants showed hyperproductivity of $\alpha$-amylase nor protease.

TABle II. Transfer of 0 -Amylase HyperPRODUCTIVITY IN C108 AND A2 BY DNA MEdiated Transformation

\begin{tabular}{lcrc}
$\begin{array}{c}\text { DNA } \\
\text { donor } \\
\text { strain }\end{array}$ & $\begin{array}{c}\text { DNA } \\
\text { recipient } \\
\text { strain }\end{array}$ & $\begin{array}{c}\text { No. of Cyc-r } \\
\text { or Amp-r } \\
\text { transformants } \\
\text { tested }\end{array}$ & $\begin{array}{c}\text { Score for } \\
\text { h-amylase }\end{array}$ \\
\hline C108 & 6160 & 420 & 0 \\
& NA64 & 300 & 0 \\
& B7 & 120 & 5 \\
& TM23 & 420 & 26 \\
\hline A2 & 6160 & 420 & 0 \\
& TM23 & 420 & 34 \\
\hline
\end{tabular}

c Phenotypical D-cycloserine-resistant characteristic.

$b$ Phenotypical ampicillin-resistant characteristic.

DNA from $\mathrm{Cl} 108$ was further transferred into NA64, B7 and TM23 (Table II). Neither $\alpha$-amylase nor protease hyperproducers was isolated among Cyc-r transformants of NA64. On the contrary, 5 and 260 -amylase and protease hyperproducers were isolated from 120 and 420 Cyc-r transformants of B7 and TM23, respectively. The hyperproductivity of $\alpha$ amylase and that of protease were co-transferred. DNA from A2 was transferred into TM23 and $\dot{\alpha}$-amylase hyperproducers were isolated from Amp-r transformants in a ratio of 34/420. Because high concentration of transforming DNAs (about $1 \mu \mathrm{g} / \mathrm{ml}$ ) was employed, these ratios in the hyperproductivity and antibiotic resistance were estimated to be 
similar to those found in double transformations between two independent genetic markers. These results suggest that hyperproduction of $\alpha$-amylase in A2 and $\alpha$-amylase and protease in $\mathrm{C} 108$ was independent of antibiotic resistance. The genetic elements for hyperproductivity in the two strains (A2 and C108) were tentatively named A-2 and C-108, respectively.

Synergistic effect with other regulatory genes stimulating production of $a$-amylase

The genetic elements A-2 and C-108 were transferred in TM23 which contained four regulatory genes: amy $R 3$, amyS, tmrA7 and pap-SI, ${ }^{24}$ and synergistic effects with these genes in the production of $\alpha$-amylase were studied. Amp-r and Cys-r transformants obtained were cultured in $\mathrm{BY}$ medium containing $4 \%$ starch at $30^{\circ} \mathrm{C}$ for $48 \mathrm{hr}$. Among them, strain 630 in Cyc-r transformants produced $2 \sim 3$ times as much $\alpha$-amylase and strain 515 in Amp-r transformants produced about 1.5 times as much $\alpha$-amylase as did TM23. Furthermore, the hyperproductivity of $\alpha$-amylase and protease in $\mathrm{C} 108$ was transferred into strain 515. Strain B12, one of Cyc-r transformants of strain 515 , produced about $4,600 \mathrm{U}$ of $\alpha$-amylase and $1,100 \mathrm{U}$ of protease per $\mathrm{ml}$ of culture medium. These results indicate that A-2 and C-108 showed a synergistic effect on production of a-amylase and the two genes were different from regulatory genes contained in TM23. Strain B12 is expected to carry at least six kinds of regulatory genes and it

\section{Table III. Synergistic EFfects of Regulatory} Genes Stimulating Production of EXtracellular $\alpha$-Amylase

\begin{tabular}{|c|c|c|c|c|c|c|}
\hline \multirow{2}{*}{ Strain } & \multicolumn{5}{|c|}{ Regulatory genes } & \multirow{2}{*}{$\begin{array}{l}\text { Pro- } \\
\text { duction } \\
8 \text { of } \alpha- \\
\text { amylase } \\
(\mathrm{U} / \mathrm{ml})\end{array}$} \\
\hline & $a m r R$ & $n r A 7$ & $\operatorname{amy} S_{p}$ & pap $-S I$ & $A-2$ & \\
\hline TM23 & - & e & 0 & 0 & & 1,200 \\
\hline 515 & 0 & - & 0 & 0 & 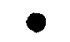 & 1,800 \\
\hline 630 & 0 & - & 0 & - & & 2,700 \\
\hline$B 12$ & - & $\bullet$ & - & - & $\bullet$ & 4,600 \\
\hline
\end{tabular}

- The regulatory gene is assumed to be included in the strain. produced about 450 times as much $\alpha$-amylase as original strain 6160 , showing the synergistic effects of each regulatory gene (Table III).

The transfer of Amp-r from A2 to 630 and of pap-9 mutation from. YY88 to 630 and 515 did not result in increased production of $\alpha$ amylase compared to parental strains.

\section{Isolation of strain $630 T 2$}

Although strains TM23, 630, 515 and B12 should carry tunicamycin resistant characteristic as shown in Table III, larger colonies of the four strains on nutrient broth agar plates containing $5 \mu \mathrm{g} / \mathrm{ml}$ of tunicamycin ${ }^{8)}$ were selected during single colony isolation. Among them, 630T2, obtained from strain 630, produced about $7,000 \mathrm{U} / \mathrm{ml}$ of $\alpha$-amylase while protease production was reduced to half of that of strain 630 .

\section{Isolation of T2N26, an a-amylase extrahyper producer}

Table IV, $\alpha$-Amylase and Protease Production By Mutants ObTaINed from 630T2

\begin{tabular}{|c|c|c|c|c|c|}
\hline \multirow{2}{*}{ Strain } & \multicolumn{2}{|c|}{ Production of } & Strains & \multicolumn{2}{|c|}{ Production of } \\
\hline & $\begin{array}{c}\alpha \text {-Amylase } \\
(\mathrm{U} / \mathrm{m} l)\end{array}$ & $\begin{array}{l}\text { Protease } \\
(\mathrm{U} / \mathrm{ml})\end{array}$ & & $\begin{array}{l}\text { Amylase } \\
(\mathrm{U} / \mathrm{ml})\end{array}$ & $\begin{array}{l}\text { Protease } \\
(\mathrm{U} / \mathrm{ml})\end{array}$ \\
\hline $\mathrm{T} 2 \mathrm{~N} 1$ & 2,000 & 110 & T2N21 & 12,500 & 210 \\
\hline 2 & 4,000 & 190 & 22 & 4,600 & 180 \\
\hline 3 & 4,400 & 180 & 23 & 4,200 & 180 \\
\hline 4 & 2,300 & 200 & 24 & 11,800 & 280 \\
\hline 5 & 3,800 & 200 & 25 & 9,000 & 220 \\
\hline 6 & 2,800 & 160 & 26 & 13,600 & 210 \\
\hline 7 & 4,500 & 160 & 27 & 10,100 & 170 \\
\hline 8 & 2,200 & 230 & 28 & 3,900 & 220 \\
\hline 9 & 3,700 & 200 & 29 & 4,400 & 160 \\
\hline 10 & 1,700 & 240 & 30 & 4,600 & 210 \\
\hline 11 & 3,400 & 190 & 31 & 12,000 & 140 \\
\hline 12 & 1,600 & 160 & 32 & 3,500 & 140 \\
\hline 13 & 4,600 & 240 & 33 & 1,100 & 11 \\
\hline 14 & 4,500 & 130 & 34 & 11,000 & 200 \\
\hline 15 & 1,400 & 96 & 35 & 12,500 & 240 \\
\hline 16 & 4,500 & 160 & 36 & 2,800 & 100 \\
\hline 17 & 10,000 & 150 & 37 & 11,100 & 190 \\
\hline 18 & 4,100 & 190 & 38 & 4,400 & 260 \\
\hline 19 & 2,900 & 84 & 39 & 3,800 & 230 \\
\hline 20 & 3,000 & 56 & $630 T 2$ & 7,000 & 210 \\
\hline
\end{tabular}

Cells were cultured in $\mathrm{ABY}$ medium at $30^{\circ} \mathrm{C}$ for $48 \mathrm{hr}$. $\alpha$-Amylase and protease activities in the culture fluids were assayed. 
To isolate superior $\alpha$-amylase producers, 630T2 cells grown in BY medium was treated with NTG. The mutagenized cells were plated on BY medium agar plates containing $1 \%$ casein. A total 420 colonies, which produced halos smaller than the halo of 630T2 strain, were primarily selected from 6,000 colonies. Among the 420 colonies, 39 colonies showed large halos of $\alpha$-amylase on BY medium agar plates containing $1 \%$ strach. They were cultured in ABY medium. The production of enzymes by the 39 strains and $630 \mathrm{~T} 2$ is shown in Table 4. Strain 26 produced the highest amount of $\alpha$-amylase among the 39 strains, and the strain was named T2N26. The phenotypic characteristic(s) acquired in $\mathrm{T} 2 \mathrm{~N} 26$ by NTG treatment of $630 \mathrm{~T} 2$ was tentatively named $\mathrm{N}-26$.

B12 was also treated with NTG. Colonies having reduced halos of protease activity were collected, but no $\alpha$-amylase overproducer than strain B12 was isolated.

Time course of $\alpha$-amylase production and analysis of extracellular proteins produced

Figure 1 shows the time course of $\alpha$-amylase production by strains $6160, \mathrm{C} 108, \mathrm{TM} 23$, 630T2 and T2N26. Parental strains 6160 and $\mathrm{C} 108$, produced only about 10 and $60 \mathrm{U} / \mathrm{ml}$, respectively, of $\alpha$-amylase in cultures at $30^{\circ} \mathrm{C}$ for $48 \mathrm{hr}$. On the other hand, T2N26 produced about $16,000 \mathrm{U} / \mathrm{ml}$ of $\alpha$-amylase by stepwise accumulation of at least six regulatory genes stimulating production of $\alpha$-amylase into strain 6160. T2N26 produced about $25,000 \mathrm{U} / \mathrm{ml}$ of a-amylase in $72 \mathrm{hr}$ at $30^{\circ} \mathrm{C}$. This concentration of the enzyme corresponds approximately to a solution of $2.5 \mathrm{mg} / \mathrm{ml}$ of pure $\alpha$-amylase.

Compositions of extracellular proteins produced by strains $6160, \mathrm{C} 108, \mathrm{TM} 23,630 \mathrm{~T} 2$ and T2N26 were analyzed by SDS disc gel - electrophoresis (Fig. 2). The major protein band shown by arrow $F$ in strain 6160 was flagellin monomer having a molecular weight of about 36,000..$^{15}$ An $\alpha$-amylase bands was not detected in the culture fluids of strains 6160 and $\mathrm{C} 108$. On the contrary, a clear band

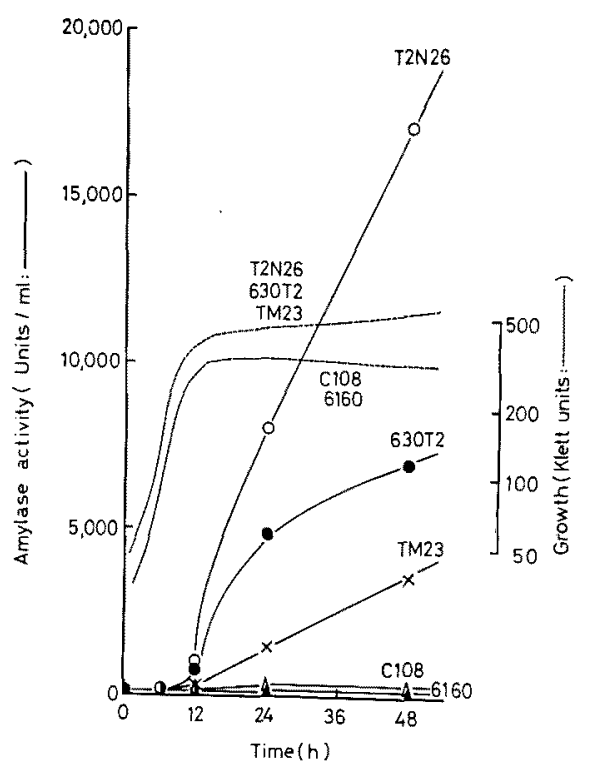

Fig, 1. Time Course of Extracellular $\alpha$-Amylase Production by Strains 6160, C108, TM23, 630T2 and T2N26.

Strains 6160 and C108 were cultured in BY medium at $30^{\circ} \mathrm{C}$. When the two strains were cultured in $\mathrm{ABY}$ medium, $\alpha$-amylase activity in the culture fluids could not be assayed by the soluble starch that remained in fluids because of the small production of $\alpha$-amylase. Strains TM23, 630T2 and T2N26 were cultured in $\mathrm{ABY}$ medium at $30^{\circ} \mathrm{C}$.

of $\alpha$-amylase (arrow A) appeared in the culture fluid of TM23, and quite dense bands of enzyme were observed in 630T2 and T2N26. Alkaline protease bands (arrow $\mathrm{P}$ ) were detected in the culture fluids of strains C108, 630T2 and $\mathrm{T} 2 \mathrm{~N} 26$.

\section{DISCUSSION}

We isolated many mutants resistant to Dcycloserine $(200 \mu \mathrm{g} / \mathrm{ml}$ of culture medium), penicillin $(2 \mu \mathrm{g} / \mathrm{ml})$ and ampicillin $(1 \mu \mathrm{g} / \mathrm{ml})$, from $B$. subtilis 6160 , in an attempt to obtain hyperproducers of extracellular $\alpha$-amylase. Among them, strain C108 (a D-cycloserine resistant mutant) and $\mathrm{A} 2$ (an ampicillin resistant mutant) were selected. The former produced about 5 times as much $\alpha$-amylase and about 80 times as much protease as 6160 , the latter produced about 6 times as much $\alpha$-amylase as 


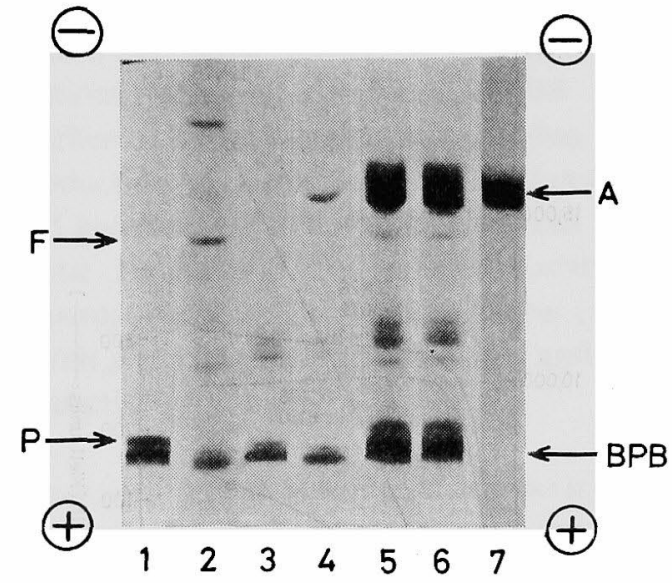

FIG. 2. SDS Disc Gel Electrophoretic Analysis of Extracellular Proteins Produced by Strains 6160, C108, TM23, 630T2 and T2N26.

Cells were cultured in media remarked in the footnote of Fig. 1 at $30^{\circ} \mathrm{C}$ for $48 \mathrm{hr}, 1$, Alkaline protease commercially obtained (arrow P); 2, Culture fluid of strain 6160; 3, Strain C108; 4, Strain TM23; 5, Strain 630T2; 6, Strain T2N26, and 7, Purified $\alpha$-amylase (arrow A). Arrow F, flagellin monomer of strain 6160 ; BPB, bromophenol blue. $0.1 \mathrm{ml}$ of each fluid was applied.

strain 6160 . The hyperproductivity of $\alpha$ amylase in the two strains could be separated from Cyc-r and Amp-r by DNA mediated transformation. Although these mutations brought about only small elevation of $\alpha$ amylase production in parental 6160 strain, they expressed synergistic effects when they were introduced into proper strains carrying other regulatory genes as shown by other combinations of regulatory genes ${ }^{6,7,8,24}$ and $\alpha$ amylase hyper and extrahyper producing strains were able to be isolated. According to the procedure shown in Fig. 3, many regulatory genes stimulating production of $\alpha$-amylase were introduced into strain 6160 using DNA mediated transformation and mutation. Final strain T2N26 obtained in the present experiment produced 1,500 2,000 fold more $\alpha$-amylase compared to the original 6160 strain. Though genetic analysis of T2N26 has not been completed, it is expected that this strain carries at least six genetic factors responsible for extrahyper production of $\alpha$-amylase: amyR3, amyS, tmrA7, pap-S1, C-108 and N-26.

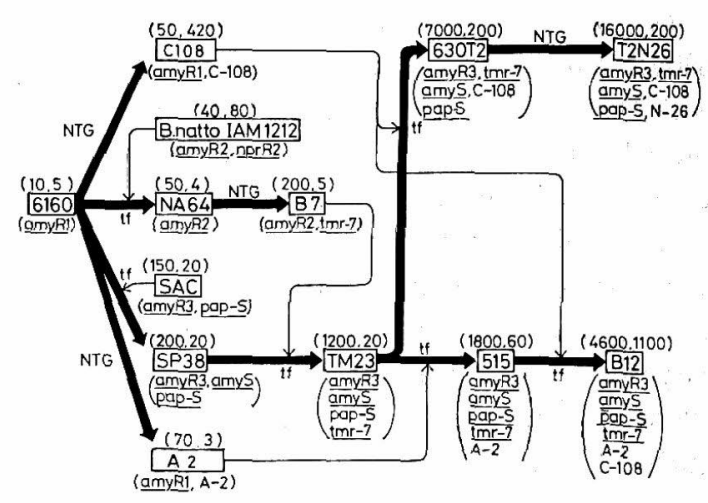

FIG. 3. Procedure to Construct $\alpha$-Amylase Overproducing Strains.

Names of strains are given in rectangles and genetic change of a strain to another is shown by a thick arrow (NTG: by NTG treatment, tf: by DNA mediated transformation). The thin arrows pointing to the thick arrows (tf) imply that the genetic factors obtained from donor strains were transferred to the recipient strains. Numerals above rectangles represent production $(\mathrm{U} / \mathrm{ml})$ of $\alpha$-amylase (the former) and protease (the latter). Possible genetic makers stimulating production of $\alpha$-amylase and protease included in strains are shown below rectangles. SAC: $B$. subtilis var. amylosacchariticus.

At $20 \mathrm{hr}$ after inoculation, when T2N26 was producing $\alpha$-amylase at a maximum ratio, ${ }^{3} \mathrm{H}$ leucine was added and incubated for an additional $20 \mathrm{~min}$ at $30^{\circ} \mathrm{C}$. $\alpha$-Amylase tritiated among this period, measured by immunoprecipitation with rabbit antiserum against $\alpha$-amylase, was $7 \sim 10 \%$ of total protein tritiated which was precipitated by $5 \%$ hot trichloroacetic acid solution (Yamauchi et al., unpublished).

In addition of mechanisms directly involved in protein synthesis, other mechanisms by which proteins pass through the cytoplasmic membrane and the cell wall should also play important roles in production of extracellular enzymes. Their productivities could be a reflection of the activities of these mechanisms in which many regulatory factors would be included. The extrahyper production of $\alpha-$ amylase in strain T2N26 was resulted in a cooperation of at least six regulatory genes and individual genes or genes absence of any one or more of them could not bring about an 
enzyme-producing power as strong as that of T2N26. This phenomenon may indicate that each of these regulatory factors has a different role in the process of $\alpha$-amylase synthesis and secretion. If so, biochemical studies on the activity of these genetic factors may aid in clarifying the synthesis and secretion of extracellular enzymes.

The fact that synergistic effects of regulatory genes were observed in $\alpha$-amylase production in $B$. subtilis suggests that such effects of those genetic factors may also distribute in production of many other extracellular enzymes by other microorganisms. If this is the case, the methods and idea which we adopted in this study may serve as a powerful tool for improving microorganisms in production of extracellular enzymes for practical uses.

Acknowledgments. We thank Prof. G. Tamura, Department of Agricultural Chemistry, Tokyo University, for the gift of tunicamycin. This work was supported in part by grants-in-aid for Science Research from the Ministry of Education, Science and Culture, Japan.

\section{REFERENCES}

1) H. Matsuzaki, K. Yamane, K. Yamaguchi, Y. Nagata and B. Maruo, Biochim. Biophys. Acta, 365, 235 (1974).

2) H. Matsuzaki, K. Yamane and B. Maruo, Biochim. Biophys. Acta, 365, 248 (1974).

3) K. Yamane and B. Maruo, Biochim. Biophys. Acta, 393, 571 (1974).

4) K. Yamaguchi, H. Matsuzaki and B. Maruo, J. Gen. Appl. Microbiol., 15, 97 (1969).
5) S. Yuki, Biochem. Biophys. Res. Commun., 31, 182 (1968).

6) Y. Yoneda, K. Yamane and B. Maruo, Biochem. Biophys. Res. Commun., 50, 765 (1973).

7) Y. Yoneda and B. Maruo, J. Bacteriol., 124, 48 (1975).

8) T. Sasaki, M. Yamasaki, B. Maruo, Y. Yoneda, K. Yamane, A. Takatsuki, and G. Tamura, Biochem. Biophys. Res. Commun., 70, 125 (1976).

9) S. Nomura, K. Yamane, T. Sasaki, M. Yamasaki, G. Tamura and B. Maruo, J. Bacteriol, 136, 818 (1978).

10) J. Sekiguchi, N. Takada and O. Okada, J. Bacteriol., 121, 688 (1975).

11) F. Kunst, M. Pascal, J. Lepesant-Kejzlarova, J.-A. Lepesant, A. Billault, and R. Dedonder, Biochimie, 56, 1481 (1974).

12) A. Takatsuki, K. Kohno, and G. Tamura, Agric. Biol. Chem., 39, 2089 (1975).

13) G. Tamura, T. Sasaki, M. Matsuhashi, A. Takatsuki, and M. Yamasaki, Agric. Biol. Chem., 40, 447 (1976).

14) H. A. I. McArthur, F. M. Roberts, I. C. Honcock, and J. Baddiley, FEBS Lett., 86, 193 (1978).

15) D. Ayusawa, Y. Yoneda, K. Yamane and B. Maruo, J. Bacteriol., 124, 459 (1975).

16) M. Steinmetz, F. Kunst and R. Dedonder, Molec. gen. Genet., 148, 281 (1976).

17) K. Kadowaki, J. Hosoda and B. Maruo, Biochim. Biophys. Acta, 103, 311 (1965).

18) E. A. Adelberg, M. Mandel and G. C. C. Chen, Biochem. Biophys. Res. Commun., 18, 788 (1965).

19) H. Fuwa, J. Biochem. (Tokyo), 41, 583 (1954).

20) M. Nakamura, J. Agric. Chem. Sci. Jpn., 33, 586 (1959).

21) H. Saito and K. Miura, Biochim. Biophys. Acta, 72, 619 (1963).

22) H. Yoshikawa, Proc. Natl. Acad. Sci. USA., 65, 206 (1970).

23) U. K. Laemmli, Nature (London), 227, 680 (1970).

24) Y. Yoneda, Appl. Envirom. Microbiol., in press. 